\title{
The impact of pharmacist interventions on osteoporosis management: a systematic review
}

\author{
M. N. Elias • A. M. Burden • S. M. Cadarette
}

Received: 14 September 2010 / Accepted: 25 February 2011 /Published online: 1 July 2011

(C) The Author(s) 2011. This article is published with open access at Springerlink.com

\begin{abstract}
Summary We completed a systematic review of the literature to examine the impact of pharmacist interventions in improving osteoporosis management. Results from randomized controlled trials suggest that pharmacist interventions may improve bone mineral density testing and calcium intake among patients at high risk for osteoporosis.

Introduction Pharmacists play a key role in many healthcare systems by helping patients manage chronic diseases. We completed a systematic review of the literature to identify randomized controlled trials (RCTs) that have examined the impact of pharmacy interventions in narrowing two gaps in osteoporosis management: identifying at-risk individuals and improving adherence to therapy.

Methods We searched the electronic databases of EMBASE, HealthStar, International Pharmaceutical Abstracts, MEDLINE, and PubMed from database development to April 2010, examined grey literature, and completed manual searches of reference lists to identify English-language research that examined osteoporosis management interventions within pharmacy practice. Results from RCTs were abstracted and assessed for bias.

Results We identified 25 studies that examined pharmacist interventions in osteoporosis management: 16 cohort, 5 crosssectional, 1 historical/ecological control, and 3 RCTs. RCT interventions included osteoporosis educational and counseling programs, screening by pharmacists based on risk factor assessment or bone mineral density testing, and physician contact or recommendations for patients to follow-up with a general practitioner. Results from the three RCTs suggest that pharmacist interventions may improve bone mineral density testing (targeted screening) and calcium intake among patients
\end{abstract}

M. N. Elias · A. M. Burden $\cdot$ S. M. Cadarette $(\triangle \nabla)$

Leslie Dan Faculty of Pharmacy, University of Toronto,

144 College Street,

Toronto, ON M5S 3M2, Canada

e-mail: s.cadarette@utoronto.ca at high risk for osteoporosis. However, two of the three RCTs had high risk of bias, and no study examined the impact of pharmacist intervention on osteoporosis treatment adherence. Conclusions Data support the potential role for pharmacists to help reduce gaps in osteoporosis management through improved identification of high-risk patients. More research is needed to examine pharmacist interventions on osteoporosis treatment adherence.

Keywords Osteoporosis - Outcome assessment . Pharmacists $\cdot$ Review Systematic

\section{Introduction}

Two gaps in osteoporosis management are well documented: (1) most patients at high risk for fracture are not identified for treatment, and (2) adherence to osteoporosis pharmacotherapy is suboptimal [1-3]. For example, post-fracture osteoporosis screening and treatment rates are below $20 \%$ in most settings $[1,4]$, and approximately half of the patients who start osteoporosis pharmacotherapy discontinue treatment within the first year of therapy $[2,3]$. In theory, pharmacists may play a role in narrowing gaps in osteoporosis diagnosis and treatment adherence. First, pharmacists may help identify high-risk patients, such as those on chronic glucocorticoid therapy who can then be targeted for bone mineral density (BMD) testing and treatment initiation. Second, pharmacists can provide counseling and educate patients on medication use, fall prevention, and the importance of calcium, vitamin $\mathrm{D}$, exercise, and adherence to therapy. A recent review identified that non-drug interventions by healthcare professionals improved quality of life, treatment adherence, and calcium intake among community-dwelling postmenopausal women with osteoporosis; however, no study within the review examined pharmacist interventions [5]. We therefore completed a systematic review of the literature to identify all 
articles that have examined the impact of pharmacist interventions in osteoporosis management. The purpose of our review was to use results from randomized controlled trials (RCTs) to determine if pharmacy interventions can help narrow two gaps in osteoporosis management: identifying atrisk individuals and improving adherence to therapy.

\section{Methods}

Data sources and study eligibility

The electronic databases EMBASE, HealthStar, International Pharmaceutical Abstracts, MEDLINE, and PubMed were searched from database development to April 2010 to identify all English language publications that examined pharmacist interventions in osteoporosis management. Search terms were adapted from a Cochrane Collaboration review [6] and selected upon consultation with a library scientist, Appendix Table 4. Any intervention that utilized a pharmacist to improve osteoporosis management was eligible. Manual searches of reference lists from eligible studies and a grey literature search were also completed $[7,8]$. Our grey literature search targeted government, research institution, professional association, and osteoporosis foundation websites to try to capture research published as a report and not accessible through traditional research databases, Appendix Table 5. Abstracts, commentaries, letters, news articles, and review papers were excluded. Titles and abstracts were reviewed for relevance by two authors (MNE, AMB), and discrepancies were settled through consultation with a third author (SMC). All relevant publications were identified, yet only RCTs were eligible for detailed review. We therefore identified all papers that included a pharmacist in the context of osteoporosis management, yet focused on RCTs as these may provide the highest quality of evidence [8].

\section{RCT data abstraction}

Study characteristics including research design, setting, pharmacist training, patient inclusion criteria, patient recruitment, intervention details, and outcomes were abstracted by two authors (MNE, AMB) and confirmed by a third author (SMC). Since the ultimate goal of identifying high-risk patients is treatment to reduce fracture risk, our a priori focus was on process of care outcomes related to improved identification of at-risk individuals (e.g., BMD testing and physician follow-up) and osteoporosis treatment initiation. We had intended to examine the impact of pharmacist interventions on osteoporosis treatment adherence; however, no relevant study was identified. After the identification of relevant literature, we decided to summarize information concerning improvements in calcium and vitamin D intake or supplementation.
Qualitative assessment of risk of bias

We qualitatively examined the threats to internal validity for each trial based on risk for allocation bias, attrition bias, detection bias, and performance bias $[8,9]$. Following recent guidelines to improve terminology in non-experimental research [10], we grouped these four potential biases into two types: (1) selection bias, related to allocation and attrition, and (2) information bias, related to detection and performance. Allocation bias occurs when randomization fails such that comparison groups differ on important prognostic variables. Attrition bias occurs when patients who continue to be followed are systematically different from those who are lost to follow-up in ways that impact outcomes. Detection and performance biases are classified as different types of information bias - biases that occur when there are systematic differences in the completeness or accuracy of data that lead to differential misclassification of patient characteristics, exposure, or outcomes [10]. Detection bias results from differential outcome assessment between comparison groups, and performance bias results from unequal provision of care between comparison groups other than differences related to the main intervention [9]. We then classified the level of risk of bias based on whether there was little evidence that the bias would impact study results (low) or if some evidence suggested that the bias may have impacted study results (high). We did not use a more fine assessment to identify medium risk of bias.

\section{Results}

Of the 611 unique English language publications identified from the database searches, 118 were pulled for detailed review and one additional publication [11] was found from the manual search of reference lists, Fig. 1. No grey literature was identified. Of the 119 publications reviewed, 25 examined pharmacist interventions in osteoporosis management: 16 cohort [12-27], five cross-sectional [28-32], one historical/ ecological control [33], and three RCTs [34-36]. Of the three RCTs, two were cluster RCTs that involved the randomization of pharmacies/pharmacists rather than randomization of single patients $[34,35]$. Characteristics of the three RCTs are summarized in Table 1, and potential biases are summarized in Table 2.

\section{Cluster RCT in Australia}

Crockett et al. completed a cluster RCT in New South Wales, Australia whereby all 86 community pharmacists in six suburb and six rural communities were invited to participate [34]. Of the pharmacists that were willing and had suitable space and staffing to participate, one pharmacist within each of the six suburban and six rural areas was randomly selected 
Fig. 1 Flow chart of literature search strategy. IPA International Pharmaceutical Abstracts. *no grey literature identified from our primary search (Appendix Table 5)

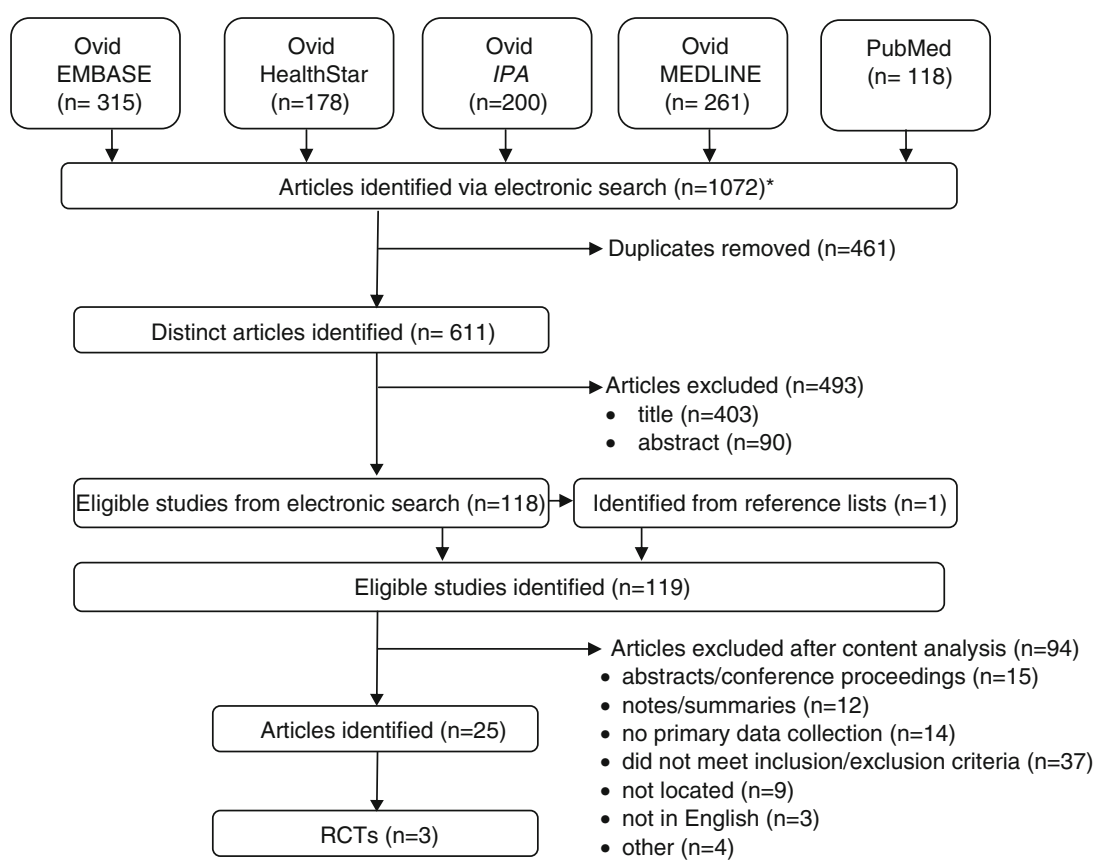

for participation. Each of the 12 randomly selected pharmacists was then randomized into one of two groups: (1) non$B M D$ group, pharmacists offered education, counseling, and risk assessment based on patient questionnaire responses only and (2) BMD group, pharmacists offered education, counseling, and risk assessment based on questionnaire responses and forearm BMD test results. The forearm BMD tests were performed by a radiographer using peripheral dual-energy $\mathrm{X}$ ray absorptiometry (DXA). All 12 participating pharmacists were provided with an information package and invited to attend a 7-h training session or receive an on-site training visit. After pharmacist training, the chief research officer and project officer visited study sites to ensure adherence to protocol and service delivery consistency. Each pharmacist was asked to recruit 20 participants meeting eligibility criteria (Table 1). Participants deemed to be at medium or high risk based on questionnaire (non-BMD group) or questionnaire and BMD (BMD group) were advised to see a general practitioner. Outcomes were assessed by telephone follow-up at 3 and 6 months post-intervention. The outcomes of interest for our review included patient self-report of pharmacist recommendations (increase in calcium or vitamin D intake and need for follow-up with a general practitioner), and whether or not the patient followed through with baseline recommendations given by the pharmacist.

The internal validity of this trial is limited with high risk of bias across all four levels evaluated, Table 2. First, we note potential selection bias related to allocation: patients selfreferred into the study and there was a significant difference in recruitment success between the rural non-BMD ( $n=43$ of 60 target) and rural BMD ( $n=60$ of 60 target) pharmacies; and attrition: although $87 \%$ of participants responded at 3 months, only $20(10 \%)$ patients in total were contacted at 6 months [34]. In addition, the 6-month follow-up was targeted to those deemed at high risk at baseline, yet baseline risk assessment was differential between groups (performance bias). Finally, potential detection bias is high with outcomes based on patient self-report and the patient's ability to recall pharmacist recommendations. Despite limitations and documentation of little difference in study outcomes in terms of physician follow-up or calcium/vitamin D intake (Table 3), the study found significantly better patient satisfaction after 3 months of follow-up among those provided with the intervention that included forearm BMD testing (90\% satisfied), compared to those with the educational intervention that did not include BMD measurement (67\% satisfied) [34].

\section{Cluster RCT in USA}

McDonough et al. completed a cluster RCT of 15 community pharmacies (eight intervention, seven control) in Iowa, USA [35]. These pharmacies were part of a specialized provider network consisting of pharmacists with previous training and/or certification in drug therapy monitoring and research participation. All pharmacists in the participating pharmacies received approximately $4 \mathrm{~h}$ of training related to glucocorticoid-induced osteoporosis and were provided with a package of articles for independent study. Pharmacists within each pharmacy then used dispensing records to identify and mail invitation letters to eligible patients (aged $\geq 18$ years with the equivalent of $7.5 \mathrm{mg}$ or more of prednisone for $\geq 6$ months). Pharmacies in the control group provided "usual and customary care" to participants. Intervention group pharmacies provided 


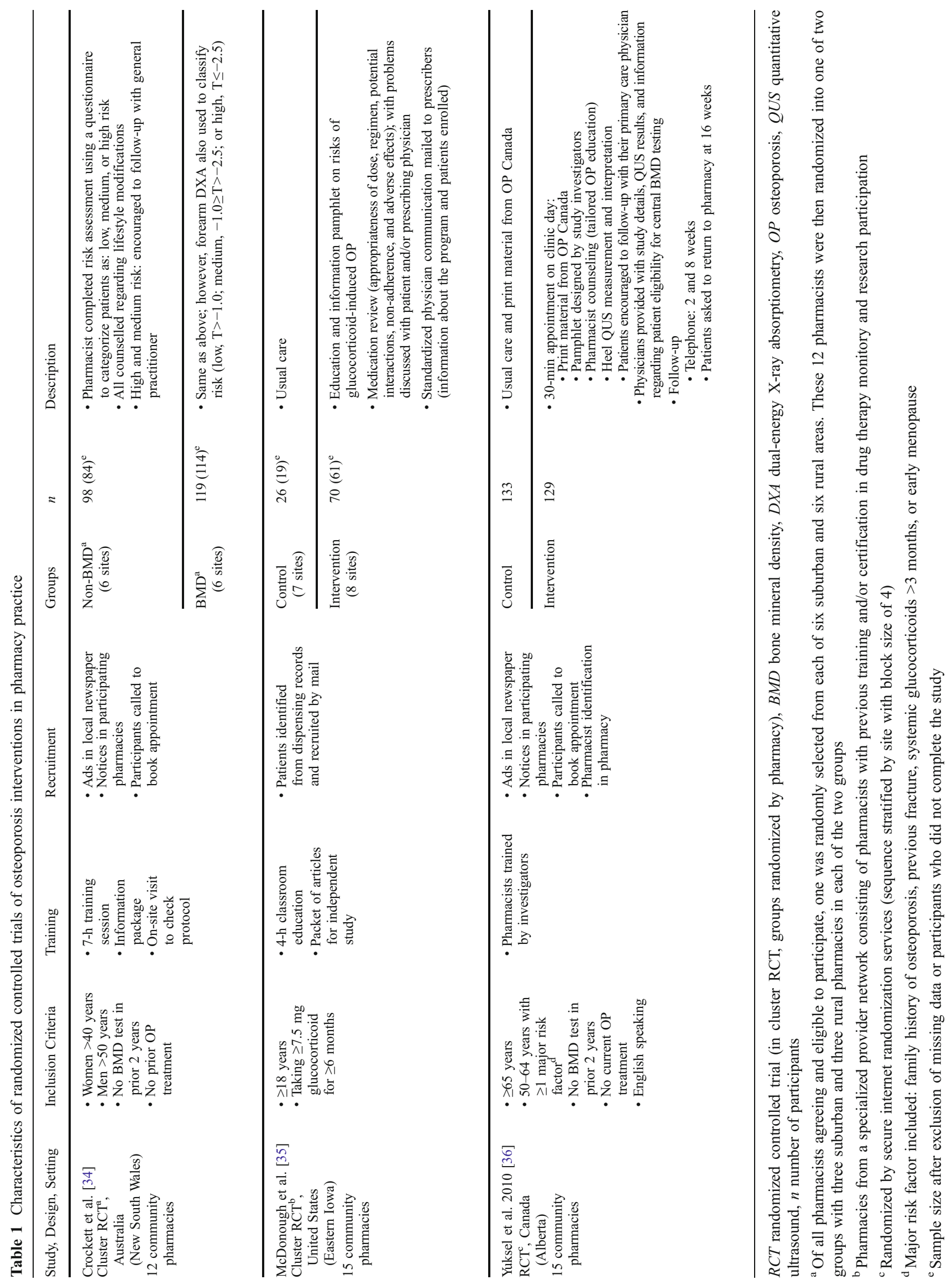


Table 2 Summary of potential risk of bias based on threats to internal validity

\begin{tabular}{|c|c|c|c|c|}
\hline \multirow[t]{2}{*}{ Study } & \multicolumn{2}{|l|}{ Selection Bias } & \multicolumn{2}{|l|}{ Information Bias } \\
\hline & Allocation $^{\mathrm{a}}$ & Attrition $^{\mathrm{b}}$ & Performance $^{c}$ & Detection $^{\mathrm{d}}$ \\
\hline $\begin{array}{l}\text { Crockett } \\
\text { et al. [34] }\end{array}$ & $\begin{array}{l}\text { High } \\
\text { - Better recruitment } \\
\text { success in BMD group } \\
\text { in rural regions ( } n=60 \\
\text { vs. } n=43 \text { ) } \\
\text { - Non-BMD group had } \\
\text { larger proportion with } \\
\text { history of low-trauma } \\
\text { fracture ( } 21 \% \text { vs. } 11 \%)\end{array}$ & $\begin{array}{l}\text { High } \\
\text { - 3-month follow-up, } 87 \% \\
\text { - 6-month follow-up, 10\%; } \\
\text { only "high-risk" followed }\end{array}$ & $\begin{array}{l}\text { High } \\
\text { - Definition of risk } \\
\text { differed between } \\
\text { groups } \\
\text { - Group 1: } \\
\text { questionnaire only } \\
\text { - Group 2: } \\
\text { questionnaire and } \\
\text { forearm BMD results }\end{array}$ & $\begin{array}{l}\text { High } \\
\text { - Self-report assessment based on } \\
\text { patient recall of pharmacist } \\
\text { recommendations and whether } \\
\text { or not they complied with the } \\
\text { pharmacist's recommendations }\end{array}$ \\
\hline $\begin{array}{l}\text { McDonough } \\
\text { et al. [35] }\end{array}$ & $\begin{array}{l}\text { High } \\
\text { - Significantly more } \\
\text { participants in } \\
\text { intervention vs. } \\
\text { control ( } n=70 \text { vs. } \\
n=26 \text { ) } \\
\text { - Intervention group } \\
\text { at higher risk, e.g.: } \\
\text { a. Female ( } 74 \% \\
\text { vs. } 58 \%) \\
\text { b. Fracture history } \\
(30 \% \text { vs. } 12 \%)\end{array}$ & $\begin{array}{l}\text { High } \\
\text { - Follow-up: } \\
\text { - } 87 \% \text { intervention } \\
\text { - } 73 \% \text { control }\end{array}$ & $\begin{array}{l}\text { Low } \\
\text { - Little evidence that the } \\
\text { "usual care" group } \\
\text { differed outside } \\
\text { the intervention } \\
\text { - All participating } \\
\text { pharmacists had } \\
\text { training or certification } \\
\text { in research participation }\end{array}$ & $\begin{array}{l}\text { Low } \\
\text { - Although outcomes are based on } \\
\text { self-report, evidence suggests } \\
\text { that self-report of DXA testing } \\
\text { and bisphosphonate use is very } \\
\text { good }[49,50]\end{array}$ \\
\hline $\begin{array}{l}\text { Yuksel } \\
\text { et al. [36] }\end{array}$ & $\begin{array}{l}\text { Low } \\
\text { - Intervention group } \\
\text { had significantly } \\
\text { more participants } \\
\text { with family history } \\
\text { of OP ( } 47 \% \text { vs. } 34 \%) \\
\text { - However, analyses } \\
\text { adjusted for age, sex, } \\
\text { and family history of OP }\end{array}$ & $\begin{array}{l}\text { Low } \\
\text { - Attrition: } n=26(20 \%) \text { in } \\
\text { intervention and } n=23 \\
(17 \%) \text { in control } \\
\text { - However, all were } \\
\text { accounted for in } \\
\text { the analyses (intention } \\
\text { to treat analysis) }\end{array}$ & $\begin{array}{l}\text { Low } \\
\text { - All participating } \\
\text { pharmacists received } \\
\text { training } \\
\text { - Control ("usual care") } \\
\text { group also given } \\
\text { educational material, } \\
\text { and thus, the effect may } \\
\text { be larger than what was } \\
\text { observed in the trial } \\
\text { when compared } \\
\text { to true "usual care" }\end{array}$ & $\begin{array}{l}\text { Low } \\
\text { - Self-report confirmed by DXA } \\
\text { report from physician (test } \\
\text { performed) and pharmacy } \\
\text { records (prescription dispensed) }\end{array}$ \\
\hline
\end{tabular}

Low risk of bias means that there is little evidence that this type of bias impacted study results. High risk of bias means that some evidence indicates that this type of bias may have impacted study results

$B M D$ bone mineral density group (peripheral DXA), $D X A$ dual-energy X-ray absorptiometry, $O P$ osteoporosis

${ }^{a}$ Allocation bias occurs when randomization fails such that comparison groups differ on important prognostic variables

${ }^{\mathrm{b}}$ Attrition bias may occur if patients who continue to be followed are systematically different from those who are lost to follow-up in ways that effect outcomes

${ }^{\mathrm{c}}$ Performance bias results from differences in the provision of care between comparison groups other than differences that relate to the main intervention

${ }^{\mathrm{d}}$ Detection bias results from differential outcome assessment between comparison groups

patients with: an information pamphlet about glucocorticoidinduced osteoporosis, education, and drug therapy monitoring. In addition, each participant's prescribing physician was mailed a standardized communication explaining the program, their patient's inclusion and any therapeutic problems identified. Study outcomes were assessed by web survey completed in the participating pharmacies at 9 months post-intervention. The outcomes of interest included change from baseline in bisphosphonate treatment, calcium supplementation, and DXA testing.
Overall risk of bias in this trial is high based on allocation and attrition (selection bias). First, we note potential allocation bias with significantly fewer participants enrolled in the control group $(n=26)$ compared to the intervention group $(n=70)$, and participants in the intervention group had higher baseline fracture risk: $74 \%$ intervention vs. $58 \%$ control were female, and $30 \%$ intervention vs. $12 \%$ control had a prior fracture; and prior osteoporosis management: $52 \%$ intervention vs. $24 \%$ control had a DXA test, and $17 \%$ intervention vs. $0 \%$ control used bisphosphonates at baseline. 
Table 3 Measured outcomes in randomized controlled studies of pharmacy interventions in osteoporosis management

\begin{tabular}{|c|c|c|c|c|c|c|}
\hline \multirow[t]{2}{*}{ Study } & \multirow[t]{2}{*}{ Follow-up details } & \multirow[t]{2}{*}{ Outcomes measured } & \multicolumn{2}{|c|}{ Group 1} & \multicolumn{2}{|c|}{ Group 2} \\
\hline & & & $n$ & $\%$ & $n$ & $\%$ \\
\hline & & & Non-B & $n=84$ & BMD, & \\
\hline \multirow[t]{4}{*}{ Crockett et al. [34] } & \multirow{4}{*}{$\begin{array}{l}\text { 3-month telephone follow-up } \\
\text { (patient self-report) }\end{array}$} & Physician follow-up & $2 / 7$ & 28.6 & $3 / 22$ & 13.6 \\
\hline & & Increase in calcium intake & $37 / 45$ & 82.2 & $29 / 38$ & 76.3 \\
\hline & & Increase in vitamin $\mathrm{D}$ intake & $18 / 21$ & 85.7 & $4 / 7$ & 57.1 \\
\hline & & & Contro & $=19$ & Interve & $n=61$ \\
\hline \multirow[t]{4}{*}{ McDonough et al. [35] } & \multirow{4}{*}{$\begin{array}{l}\text { 9-month }{ }^{\mathrm{a}} \text { web survey in pharmacy } \\
\text { (patient self-report) }\end{array}$} & DXA test & - & 39.2 & - & $19.6^{*}$ \\
\hline & & Bisphosphonate therapy & - & 10.5 & - & 9.1 \\
\hline & & Calcium supplementation & - & -6.9 & - & $17.1^{*}$ \\
\hline & & & Contro & $=133$ & Interve & $n=129$ \\
\hline \multirow[t]{7}{*}{ Yuksel et al. [36] } & \multirow{7}{*}{$\begin{array}{l}16 \text { weeks, patient self-report in } \\
\text { pharmacy (confirmed by DXA } \\
\text { report and pharmacy dispensing } \\
\text { records) }\end{array}$} & Primary outcome & & & & \\
\hline & & $\begin{array}{l}\text { DXA test or OP treatment } \\
\text { Secondary outcomes }\end{array}$ & 14 & 10.5 & 28 & $21.7^{*}$ \\
\hline & & DXA test & 13 & 9.8 & 28 & $21.7^{*}$ \\
\hline & & New osteoporosis treatment & 3 & 2.3 & 6 & 4.7 \\
\hline & & Additional patients meeting: & & & & \\
\hline & & Calcium requirements & 25 & 18.8 & 39 & $30.2 *$ \\
\hline & & Vitamin D requirements & 22 & 16.5 & 24 & 18.6 \\
\hline
\end{tabular}

$B M D$ bone mineral density group (peripheral DXA), $D X A$ dual-energy X-ray absorptiometry, $O P$ osteoporosis

$* p<0.05$

${ }^{a}$ Percent change reported (from baseline to 9 months), calculated based on numbers presented in the paper. At baseline: $24 \%$ control vs. $52 \%$ intervention had a DXA test, and $0 \%$ control vs. $17 \%$ intervention used bisphosphonates

Second, attrition bias is relevant with only 61 participants in the intervention group (87\%) and 19 participants in the control group (73\%) after exclusions based on missing data. Therefore, although this trial documented significant improvements in calcium intake from baseline in the intervention group $(+17 \%)$ compared to the control group $(-7 \%)$ [35], and smaller increase in DXA testing $(+20 \%$ intervention vs. $+39 \%$ control), it is possible that the differences result from selection bias introduced in the trial.

\section{RCT in Canada}

Yuksel et al. completed an RCT within 15 Save on Foods community pharmacies in Alberta, Canada [36]. Patients who met eligibility based on risk for osteoporosis (Table 1) and who signed informed consent were randomized using a secure internet randomization service into two groups: control or intervention. Participants in the intervention group received oral and written education about their risks for osteoporosis, had BMD measured by heel quantitative ultrasound (QUS), and were counseled regarding their risks for osteoporosis during a 30 minute session with the pharmacist. Intervention patients were also encouraged to follow-up with their primary care physician, and physicians were informed about their patient's study enrolment, QUS results, and eligibility for central DXA testing. Participants in the control group received usual care and print material from Osteoporosis Canada. The primary outcome was a composite of DXA test and/or new osteoporosis treatment initiation at 4 months post-intervention. Self-report of the primary outcome was confirmed by physician contact (copy of DXA report) and pharmacy dispensing records (initiation of new osteoporosis medication). Secondary outcomes included daily calcium and vitamin D intake.

Despite randomization, a larger proportion of patients in the intervention group reported a family history of osteoporosis ( $47 \%$ vs. $34 \%, p=0.03)$, and although not statistically significant, we note a larger proportion in the intervention group were white (66\% vs. $56 \%$ ) and were current smokers (17\% vs. 9\%) [36]. Nonetheless, authors appropriately adjusted for important baseline risk factors for osteoporosis in their analysis, including age, sex, and family history of osteoporosis. We therefore document low risk of bias related to allocation. Similarly, although 49 patients were lost to follow-up after allocation (26 intervention, 23 control), all were appropriately included in the analysis, minimizing potential attrition bias. We classify the risk of detection bias as low because self-report of the primary outcome was confirmed by physician contact and pharmacy dispensing records. Although we document low risk for performance 
bias, we note that the effects of the intervention may be larger in comparison to usual care in the "real-world," since the trial provided the control (usual care) group with information from Osteoporosis Canada. Results from this robust trial found that the pharmacist intervention increased DXA testing $(22 \%$ intervention, $10 \%$ control) and improved calcium intake (30\% intervention, 19\% control) at 4 months follow-up, Table 3 .

\section{Discussion}

Pharmacists play a key role as drug experts in many healthcare systems. Over the last 20 years, the pharmacist's role in many settings has shifted in focus from drug dispensing to patientcentered pharmaceutical care [37, 38]. Pharmacist interventions such as patient counseling, education, medication management, and referrals to other healthcare professionals have led to significant improvements in blood glucose levels among diabetic patients, blood pressure levels among antihypertensive patients, and cholesterol levels among hyperlipidemic patients [39-41]. From our review, we found that compared to "usual care," a pharmacist intervention that included patient counseling, education, QUS, and physician contact increased central DXA testing and calcium intake among individuals at high risk for osteoporosis. Although not specifically identified within the studies included in our review, a recent RCT identified that DXA testing among women aged 45-54 years significantly increased the use of osteoporosis pharmacotherapy and supplementation with calcium and vitamin D [42]. Further research is needed to determine if pharmacy interventions may also improve osteoporosis treatment initiation.

Result from studies included in our review support the use of heel QUS measurement as a feasible BMD screening method that can be utilized by pharmacists [36]. Although QUS is no better than questionnaires based on simple risk factors, such as age, body weight, and sex in predicting those likely to have low BMD [43], offering a clinical service such as BMD measurement may be important for the success of pharmacy-led osteoporosis interventions. In fact, one of the trials included in our review that compared patient satisfaction between two different pharmacist interventions found that peripheral BMD testing was important for patient recruitment and satisfaction [34]. Further research is needed to clarify the importance of BMD measurement on the success of community-based osteoporosis interventions.

Our study has many strengths, including a thorough systematic search of the literature, having two independent reviewers search for an abstract data and having a third author to resolve discrepancies. We also focused on RCT study designs. Nonetheless, our results are limited to the quality and generalizability of the RCT studies identified. In fact, due to high risk of bias in two of the RCTs under review, non-experimental studies may have yielded similar quality results. If no plan exists to disseminate interventions outside a local setting, lower-quality evidence may be acceptable in quality improvement [44]. Evidence from non-experimental studies may thus be informative for local quality improvement interventions.

Our study is also limited by qualitative assessment of risk of bias, which we ascribed as low or high risk based on our assessment of whether or not evidence existed to suggest that results may be biased. We had originally considered two quality assessment tools $[45,46]$ used in prior reviews of pharmacist interventions [8, 39-41]. However, upon the application of these quality assessment tools, we found that neither differentiated between the studies well. The first largely focused on the quality of reporting methods [45], and we found the second to be more relevant to drug interventions than healthcare interventions [46]. We therefore decided to examine the risk of bias qualitatively grouped under the main headings of information bias and selection bias, and ascribed "low risk" when we noted little evidence of potential bias, and "high risk" when we noted some evidence of potential bias. Further work to provide better quality assessment tools for healthcare interventions is needed.

Although our findings suggest that community pharmacist interventions may help to improve the identification of individuals at risk for osteoporosis through improved DXA testing, further study is important to determine the feasibility of interventions in community pharmacies. We note that the two trials with positive findings were completed in: (1) a network of pharmacies that had pharmacists with advanced training and experience in research participation [35] and (2) community pharmacies within the same pharmacy chain [36]. In addition, the one other RCT included in our review had excluded pharmacies deemed to have too few staff or insufficient space [34]. Therefore, the generalizability and feasibility to other settings need to be explored. We also note that none of the studies examined the impact of the pharmacist interventions on osteoporosis treatment adherence or considered pharmacists' experience or satisfaction with the osteoporosis management programs. Recent reviews of the literature identify that strategies that enhance patient and healthcare provider communication and treatment follow-up may be key to improving adherence to osteoporosis pharmacotherapy [5, 47, 48]. Further study is thus important to identify the impact of pharmacy interventions on treatment initiation and adherence to therapy, as well as to examine the feasibility of osteoporosis management in community pharmacy. Interventions in osteoporosis management by physicians, physiotherapists, nurses, dieticians, and other healthcare professionals working in teams have helped to improve treatment adherence and calcium intake among community-dwelling women [5] and increase BMD testing and osteoporosis treatment rates in patients post-fracture [4]. 


\section{Conclusions}

Pharmacists are in a unique position to help reduce the burden of osteoporosis by improving the identification of high-risk patients for treatment, especially those on corticosteroid therapy. Results from our review suggest that pharmacist identification and counseling of patients at risk for osteoporosis results in higher DXA testing and improvements in calcium intake. Further high-quality evidence is needed to determine the feasibility of osteoporosis management in pharmacy practice settings, to examine the comparative effectiveness of different pharmacy intervention strategies, and to address the impact of pharmacist interventions on osteoporosis treatment adherence.

Acknowledgments Authors acknowledge William Witteman, BA, MISt from the Toronto Health Economics and Technology Assessment (THETA) Collaborative at the University of Toronto for his helpful suggestions in completing systematic literature searches, and Gail Nichol, Pharmacy Liaison Librarian at the Leslie Dan Faculty of Pharmacy for her helpful expertise in medical literature databases.
This work was supported by the Canadian Institutes of Health Research (CIHR) Catalyst Grant (CPO-94434). Mary N. Elias holds a CIHR Fredrick Banting and Charles Best Scholarship Master's Award; Andrea M. Burden holds the Graduate Department of Pharmaceutical Sciences 2010 Wyeth Pharmaceutical Fellowship in Health Outcomes Research and the 2010-2011 University of Toronto Bone and Mineral Group Scholarship (Clinical); and Dr. Cadarette holds a CIHR New Investigator Award in the Area of Aging and Osteoporosis and an Ontario Ministry of Research and Innovation Early Researcher Award. Ms. Elias received funding support through the Leslie Dan Faculty of Pharmacy Student Experience Fund to present this research at the Canadian Pharmacists Association Annual meeting and through a CIHR Institute of Health Services and Policy Research Institute Community Support Travel Award to present this research at the Association of Faculties of Pharmacy in Canada's First Annual Canadian Pharmacy Education and Research Conference.

Conflicts of interest None.

Open Access This article is distributed under the terms of the Creative Commons Attribution Noncommercial License which permits any noncommercial use, distribution, and reproduction in any medium, provided the original author(s) and source are credited.

\section{Appendix}

Table 4 Search strategy for MEDLINE, EMBASE, IPA, and HealthStar done April 20, 2010

\begin{tabular}{|c|c|c|c|c|c|}
\hline & Search Terms & Ovid MEDLINE ${ }^{\mathrm{a}}$ Results & Ovid EMBASE ${ }^{\mathrm{b}}$ Results & Ovid $I P A^{\mathrm{c}}$ Results & Ovid Healthstar ${ }^{\mathrm{d}}$ Results \\
\hline 1 & *Osteoporosis/ & 19560 & 21737 & 1901 & 11099 \\
\hline 2 & osteoporos\#s.tw. & 34026 & 35796 & 1880 & 19752 \\
\hline 3 & bone loss\$.tw. & 14265 & 11657 & 315 & 8013 \\
\hline 4 & Bone Density/ & 30978 & 29744 & 251 & 18825 \\
\hline 5 & (bone adj2 (density or fragil\$)).tw. & 26293 & 24729 & 753 & 15811 \\
\hline 6 & bone mass.tw. & 10680 & 10257 & 178 & 5320 \\
\hline 7 & bmd.tw. & 14102 & 13432 & 260 & 8703 \\
\hline 8 & exp Fractures, Bone/ & 117949 & 119884 & & 77165 \\
\hline 9 & Fracture\$.tw. & 138210 & 121797 & 1370 & 87072 \\
\hline 10 & Postmenopause/ & 14361 & 27716 & 1238 & 12392 \\
\hline 11 & $\begin{array}{l}\text { (post menopaus\$ or postmenopaus\$ or } \\
\text { post-menopaus\$).tw. }\end{array}$ & 36291 & 36928 & 2055 & 26297 \\
\hline 12 & Or/1-11 & 252732 & 230223 & 4698 & 155406 \\
\hline 13 & pharmacist.mp. or exp Pharmacists/ & 11583 & 28008 & 29688 & 10896 \\
\hline 14 & exp Pharmacy/or pharmacy.mp. & 43253 & 41432 & 57688 & 31208 \\
\hline 15 & or/13-14 & 48773 & 55457 & 70287 & 36175 \\
\hline 16 & 12 and 15 & 277 & 402 & 292 & 214 \\
\hline 17 & limit 16 to English language & 268 & 351 & 288 & 210 \\
\hline 18 & remove duplicates from 17 & 261 & 315 & 200 & 178 \\
\hline
\end{tabular}

PubMed Search Terms (*Osteoporosis/OR Osteoporos OR Bone loss OR Bone Density/OR bone mass OR bmd OR exp Fractures, Bone/OR Fracture OR Postmenopause/OR (post menopause or postmenopause or post-menopause)) AND (Pharmacists/OR pharmacist); Results: 118 articles

${ }^{a}$ Ovid MEDLINE(R) (1950 to April Week 1 2010), OLDMEDLINE(R) (1947 to 1965), MEDLINE(R) Corrections, MEDLINE(R) In-Process \& Other Non-Indexed Citations (April 19 2010)

${ }^{\mathrm{b}}$ EMBASE (1980 to 2010 week 15), EMBASE Classic (1947 to 1979)

${ }^{\mathrm{c}}$ International Pharmaceutical Abstracts (1970 to April 2010)

${ }^{\mathrm{d}}$ Ovid Healthstar (1966 to March 2010) 
Table 5 Grey literature search, completed June 2009 and May 2010

Grey Literature

Centre for Health Services and Policy Research, University of British Columbia, http://www.chspr.ubc.ca/cgi-bin/pub

University of Ottawa Evidence-based Practice Center (EPC), http://www. chalmersresearch.com/old/systematic_reviews_publications.htm

Australian Safety and Efficacy Register of New Interventional Procedures - Surgical (ASERNIP-S), http://www.surgeons.org/AM/Template.cfm? Section $=$ Home $\&$ Template $=/$ Templates/HomeRACS.cfm

Department of Health and Ageing, Australian Government, http:// www.health.gov.au/internet/main/publishing.nsf/Content/healthpublicat.htm

Belgian Health Care Knowledge Centre, http://www.kce.fgov.be/ index_en.aspx?SGREF=5211

International Network of Agencies for Health Technology Assessment, http://www.inahta.org/

European network for Health Technology Assessment - EUnetHTA, http://www.eunethta.net/Public/About_EUnetHTA/

Finnish Office for Health Technology Assessment (Finohta), National Research and Development Centre for Welfare and Health (STAKES), http://finohta.stakes.fi/EN/index.htm

French National Authority for Health/Haute Autorité de santé (HAS), $\mathrm{http}: / /$ www.has-sante.fr/portail/display.jsp?id=c_5443\&pcid=c_5443

German Institute of Medical Documentation and Information (DIMDI), Federal Ministry of Health, http://www.dimdi.de/dynamic/ en/hta/db/index.htm

Health Service Executive (HSE)/Feidhmeannacht na Seirbhíse Sláinte, http://www.hse.ie/en/Publications/

Health Council of the Netherlands/De Gezondheidsraad, http://www. gezondheidsraad.nl/en

Catalan Agency for Health Technology Assessment and Research (CAHTA)/Agència d'Avaluació de Tecnologia i Recerca Mèdiques de Catalunya, http://www.gencat.net

Swedish Council on Technology Assessment in Health Care (SBU), http://www.sbu.se/en/

Aggressive Research Intelligence Facility (ARIF), Department of Public Health and Epidemiology, Department of General Practice, and the Health Services Management Centre; University of Birmingham, http://www.arif.bham.ac.uk

Agency for Healthcare Research and Quality (AHRQ) (Technology Assessments), http://www.ahrq.gov/clinic/techix.htm, http://www. ahrq.gov/clinic/epcquick.htm, http://www.ahrq.gov/clinic/epc/ epcprogress.htm

Department of Veterans Affairs Research \& Development, http://www. research.va.gov/resources/pubs/default.cfm, http://www.va.gov/ vatap/publications.htm

ECRI (Emergency Care Research Institute), http://www.ecri.org/ Institute for Clinical Systems Improvement (ICSI), http://www.icsi.org University HealthSystem Consortium (UHC), http://www.uhc.edu/

Canadian Task Force on Preventive Health Care, http://www.ctfphc. org/list_all_topics.htm

CMA Infobase, Canadian Medical Association, http://mdm.ca/ cpgsnew/cpgs/index.asp

Toward Optimized Practice (TOP), Alberta, http://www. topalbertadoctors.org/cpg.html

Aetna Clinical Policy Bulletins, http://www.aetna.com/products/rx/ pcpb_menu.html
Table 5 (continued)

Grey Literature

Intute, http://www.intute.ac.uk/

National Research Register (NRR), National Institute for Health

Research, UK, https://portal.nihr.ac.uk/Pages/NRRArchive.aspx

The Cochrane Collaboration, http://www2.cochrane.org/reviews/

Osteoporosis Canada, http://www.osteoporosis.ca/

National Osteoporosis Foundation (NOF), http://www.nof.org/

Canadian Pharmacists Association, http://www.pharmacists.ca/

National Community Pharmacists Association (NCPA), http://www. ncpanet.org/

\section{References}

1. Elliot-Gibson V, Bogoch ER, Jamal SA, Beaton DE (2004) Practice patterns in the diagnosis and treatment of osteoporosis after a fragility fracture: a systematic review. Osteoporos Int 15:767-778

2. Cramer JA, Gold DT, Silverman SL, Lewiecki EM (2007) A systematic review of persistence and compliance with bisphosphonates for osteoporosis. Osteoporos Int 18:1023-1031

3. Kothawala P, Badamgarav E, Ryu S, Miller RM, Halbert RJ (2007) Systematic review and meta-analysis of real-world adherence to drug therapy for osteoporosis. Mayo Clin Proc 82:1493-1501

4. Little EA, Eccles MP (2010) A systematic review of the effectiveness of interventions to improve post-fracture investigation and management of patients at risk of osteoporosis. Implement Sci 5:80-97

5. Lai P, Chua SS, Chan SP (2010) A systematic review of interventions by healthcare professionals on community-dwelling postmenopausal women with osteoporosis. Osteoporos Int 21:1637-1656

6. O'Donnell S, Cranney A, Wells GA, Adachi JD, Reginster JY (2006) Strontium ranelate for preventing and treating postmenopausal osteoporosis. Cochrane Database Syst Rev 18:CD005326

7. Alberani V, De Castro PP, Mazza AM (1990) The use of grey literature in health sciences: a preliminary survey. Bull Med Libr Assoc 78:358-363

8. Charrois T, Durec T, Tsuyuki RT (2009) Systematic reviews of pharmacy practice research: methodologic issues in searching, evaluating, interpreting, and disseminating results. Ann Pharmacother 43:118-122

9. Juni P, Altman DG, Egger M (2001) Systematic reviews in health care: assessing the quality of controlled clinical trials. BMJ $323: 42-46$

10. Vandenbroucke JP, von Elm E, Altman DG et al (2007) Strengthening the Reporting of Observational Studies in Epidemiology (STROBE): explanation and elaboration. Ann Intern Med 147:W163-W194

11. Taylor SJ, Crockett JA, McLeod LJ (2004) An integrated service, initiated by community pharmacists, for the prevention of osteoporosis. In Australian Government Department of Health and Ageing (ed)

12. Cerulli J, Zeolla MM (2004) Impact and feasibility of a community pharmacy bone mineral density screening and education program. J Am Pharm Assoc (2003) 44:161-167 
13. Elliott ME, Meek PD, Kanous NL et al (2002) Pharmacy-based bone mass measurement to assess osteoporosis risk. Ann Pharmacother 36:571-577

14. Goode JV, Swiger K, Bluml BM (2004) Regional osteoporosis screening, referral, and monitoring program in community pharmacies: findings from Project ImPACT: Osteoporosis. J Am Pharm Assoc (2003) 44:152-160

15. Hall LN, Shrader SP, Ragucci KR (2009) Evaluation of compliance with osteoporosis treatment guidelines after initiation of a pharmacist-run osteoporosis service at a family medicine clinic. Ann Pharmacother 43:1781-1786

16. Ho C, Cranney A, Campbell A (2006) Measuring the impact of pharmacist intervention: results of patient education about osteoporosis after fragility fracture. Can J Hosp Pharm 59:184-193

17. Johnson JF, Koenigsfeld C, Hughell L, Parsa RA, Bravard S (2008) Bone health screening, education, and referral project in northwest Iowa: creating a model for community pharmacies. J Am Pharm Assoc (2003) 48:379-387

18. Law AV, Shapiro K (2005) Impact of a community pharmacistdirected clinic in improving screening and awareness of osteoporosis. J Eval Clin Pract 11:247-255

19. MacLaughlin EJ, MacLaughlin AA, Snella KA et al (2005) Osteoporosis screening and education in community pharmacies using a team approach. Pharmacotherapy 25:379-386

20. Nadrash TA, Plushner SL, Delate T (2008) Clinical pharmacists' role in improving osteoporosis treatment rates among elderly patients with untreated atraumatic fractures. Ann Pharmacother 42:334-340

21. Naunton M, Peterson GM, Jones G (2006) Pharmacist-provided quantitative ultrasound screening for rural women at risk of osteoporosis. Ann Pharmacother 40:38-44

22. Newman ED, Hanus P (2001) Improved bone health behavior using community pharmacists as educators: the Geisinger health system community pharmacist osteoporosis education program. Dis Manag Health Outcomes 9:329-335

23. Riley K, Martin J, Wazny LD (2005) Impact of pharmacist intervention on osteoporosis treatment after fragility fracture: positive effect of pharmacist information program shown in pilot study. Can Pharm J 138:37-43

24. Siow JY, Lai PS, Chua SS, Chan SP (2009) The impact of pharmacist intervention on the use of activated vitamin D in a tertiary referral hospital in Malaysia. Int J Pharm Pract 17:305-311

25. Stroup JS, Rivers SM, Abu-Baker AM et al (2007) Two-year changes in bone mineral density and T scores in patients treated at a pharmacist-run teriparatide clinic. Pharmacotherapy 27:779-788

26. Summers KM, Brock TP (2005) Impact of pharmacist-led community bone mineral density screenings. Ann Pharmacother 39:243-248

27. Peters S, Singla D, Raney E (2006) Impact of pharmacistprovided osteoporosis education and screening in the workplace. J Am Pharm Assoc (2003) 46:216-218

28. Chaiyakunapruk N, Laowakul A, Karnchanarat S, Pikulthong N, Ongphiphadhanakul B (2006) Community pharmacy-based implementation and evaluation of an osteoporosis self-assessment tool for Asians. J Am Pharm Assoc (2003) 46:391-396

29. Gloth FM, Simonson W (2008) Osteoporosis is underdiagnosed in skilled nursing facilities: a large-scale heel BMD screening study. J Am Med Dir Assoc 9:190-193

30. Liu Y, Nevins JC, Carruthers KM et al (2007) Osteoporosis risk screening for women in a community pharmacy. J Am Pharm Assoc (2003) 47:521-526

31. Wilcock M, MacMahon D, Woolf A (2005) Use of medicines that influence falls or fractures in a residential home setting. Pharm World Sci 27:220-222
32. Lata PF, Binkley NC, Elliott ME (2002) Acceptability of pharmacy-based bone density measurement by women and primary healthcare providers. Menopause 9:449-455

33. Naunton M, Peterson GM, Jones G, Griffin GM, Bleasel MD (2004) Multifaceted educational program increases prescribing of preventive medication for corticosteroid induced osteoporosis. $\mathrm{J}$ Rheumatol 31:550-556

34. Crockett JA, Taylor SJ, McLeod LJ (2008) Patient responses to an integrated service, initiated by community pharmacists, for the prevention of osteoporosis. Int J Pharm Pract 16:65-72

35. McDonough RP, Doucette WR, Kumbera P, Klepser DG (2005) An evaluation of managing and educating patients on the risk of glucocorticoid-induced osteoporosis. Value Health 8:24-31

36. Yuksel N, Majumdar SR, Biggs C, Tsuyuki RT (2010) Community pharmacist-initiated screening program for osteoporosis: randomized controlled trial. Osteoporos Int 21:391-398

37. Hepler CD, Strand LM (1990) Opportunities and responsibilities in pharmaceutical care. Am J Hosp Pharm 47:533-543

38. Jones EJ, Mackinnon NJ, Tsuyuki RT (2005) Pharmaceutical care in community pharmacies: practice and research in Canada. Ann Pharmacother 39:1527-1533

39. Machado M, Bajcar J, Guzzo GC, Einarson TR (2007) Sensitivity of patient outcomes to pharmacist interventions. Part I: systematic review and meta-analysis in diabetes management. Ann Pharmacother 41:1569-1582

40. Machado M, Bajcar J, Guzzo GC, Einarson TR (2007) Sensitivity of patient outcomes to pharmacist interventions. Part II: systematic review and meta-analysis in hypertension management. Ann Pharmacother 41:1770-1781

41. Machado M, Nassor N, Bajcar JM, Guzzo GC, Einarson TR (2008) Sensitivity of patient outcomes to pharmacist interventions. Part III: systematic review and meta-analysis in hyperlipidemia management. Ann Pharmacother 42:1195-1207

42. Barr RJ, Stewart A, Torgerson DJ, Reid DM (2010) Population screening for osteoporosis risk: a randomised control trial of medication use and fracture risk. Osteoporos Int 21:561-568

43. Cook RB, Collins D, Tucker J, Zioupos P (2005) Comparison of questionnaire and quantitative ultrasound techniques as screening tools for DXA. Osteoporos Int 16:1565-1575

44. Fan E, Laupacis A, Pronovost PJ, Guyatt GH, Needham DM (2010) How to use an article about quality improvement. JAMA 304:2279-2287

45. Downs SH, Black N (1998) The feasibility of creating a checklist for the assessment of the methodological quality both of randomised and non-randomised studies of health care interventions. J Epidemiol Community Health 52:377-384

46. Higgins J, Green S (eds) (2009) Cochrane Handbook for Systematic Reviews of Interventions Version 5.0.2 [updated September 2009]. Available from www.cochrane-handbook.org

47. Cadarette SM, Burden AM (2010) Measuring and improving adherence to osteoporosis pharmacotherapy. Curr Opin Rheumatol 22:397-403

48. Gleeson T, Iversen MD, Avorn J et al (2009) Interventions to improve adherence and persistence with osteoporosis medications: a systematic literature review. Osteoporos Int 20:21272134

49. Cadarette SM, Beaton DE, Gignac MAM et al (2007) Minimal error in self-report of having had DXA, but self-report of its results was poor. J Clin Epidemiol 60:1306-1311

50. Cadarette SM, Jaglal SB, Raman-Wilms L, Beaton DE, Paterson JM (2011) Osteoporosis quality indicators using healthcare utilization data. Osteoporos Int 22:1335-1342 